\title{
Structural Investigation of Humic Acids of Forest Soils by Pyrolysis-Gas Chromatography
}

\author{
Magdalena Banach-Szott $^{1 *}$, Bożena Dębska ${ }^{1}$, Erika Tobiasova ${ }^{2}$, Jarosław Pakuła ${ }^{1}$ \\ ${ }^{1}$ University of Science and Technology, Department of Biogeochemistry and Soil Science, Bydgoszcz, Poland \\ ${ }^{2}$ Slovak Agricultural University, Department of Soil Science, Nitra, Slovakia
}

Received: 18 June 2018

Accepted: 8 October 2018

\begin{abstract}
The aim of the present paper is to define the importance of the Py-GC/MS method in the study of structural composition of HAs of forest soils depending on plant litter properties (oak, spruce, thuja). Forest soil sampled from the area of Rogow Forest Experiment Department, Warsaw Agricultural University (WAU), was used for our research. The forest soil (Haplic Luvisols) was sampled in 5 replications under tree stands of: oak (Quercus robur L.), spruce (Picea abies L. Karsten) and thuja (Thuja plicata D.Don.ex. Lamb.). Humic acids (HAs) were isolated from the soil sample using the IHSS method. For the humic acids extracted from horizons Ol, A and E (AE), the spectrophotometric analyses in the UV-VIS range were performed and the elemental composition was assayed. The HA chemical composition was evaluated with the use of pyrolysis-gas chromatography/mass spectrometry (Py-GC/MS). The humic acids of Ol horizon, irrespective of the tree stand, showed higher $\mathrm{H} / \mathrm{C}$ values and lower $\mathrm{O} / \mathrm{H}$ values as compared with $\mathrm{HAs}$ from $\mathrm{A}$ and/or $\mathrm{E}$ (AE) horizons. Humic acids pyrolysis products were identified as aromatic single- and multi-ring compounds, compounds of lignin origin, phenolic compounds, polysaccharide compounds, and nitrogen-containing compounds as well as aliphatic compounds. The dominant compounds, being part of humic acids pyrolysis products, were single-ring aromatic hydrocarbons, which accounted for 58.81 to $76.20 \%$ of all the compounds identified. Generally it should be stated that the share of particular groups of compounds varied with soil depth and depended on the species of tree.
\end{abstract}

Keywords: oak, spruce, thuja, decomposition, humic acids, pyrolysis GC/MS

\section{Introduction}

Organic matter is an essential soil component determining its physical, chemical and biological properties. Both in arable fields and in forest ecosystems, the key source of organic matter is plant material at

*e-mail: mbanach@utp.edu.pl various stages of decomposition and processing, living and dead soil organisms, as well as their excrement [1]. The effect of respective plant materials on organic matter balance in those ecosystems is not the same. The problem concerns the quantity and the quality of the material introduced to soil [2-7]. In forests the chemical composition of the plant litter reaching soil depends on the tree stand species and the habitat. The highest differences in the chemical composition were observed between deciduous and coniferous vegetation. 
As reported by Kogel et al. [8], coniferous forests have a dominance of lignin compounds related to guaicol, whereas angiosperm plants also contain compounds related to syringol.

The research of the structure demonstrated that in humic acids, molecules non-decomposed lignin fragments are found [5, 9-10]. For that reason those compounds are considered one of the main precursors of aromatic carbon in humic substance molecules $[16,17]$. The basic indicators used to evaluate the properties of humic acids are elemental composition, including the values of atomic ratios: $\mathrm{H} / \mathrm{C}, \mathrm{O} / \mathrm{C}, \mathrm{N} / \mathrm{C}$ determined drawing on that composition as well as the degree of internal oxidation, coefficients of absorbance $\mathrm{A}_{2 / 4}, \mathrm{~A}_{2 / 6}, \mathrm{~A}_{4 / 6}$ and $\Delta \log \mathrm{K}$, and IR spectra, ${ }^{13} \mathrm{CNMR}$ spectroscopy $[5,9,11-14]$ as well as, as shown by, e.g., Debska et al. [3], hydrophilic-hydrophobic parameters.

Pyrolytic gas chromatography with mass spectrometry is a modern analytical method, more and more frequently applied to determine the structure of humus substances [14-20]. That technique draws on thermal degradation of a complicated structure of humus substances to simpler organic compounds that can be identified with mass spectrometry.

As reported by, e.g., de Assis et al. [18], Zhang et al. [19], Vancampenhout et al. [20, 21], and Yassir and Buurman [22], the pyrolysis of humic acids results in compounds that are lignin-derivatives (e.g., 4-methoxyphenol, 4-methylguaicol, 4-formylguaicol, dimethoxyphenol, 4-methylsyringol); polysaccharides (e.g., methylbenzofuran, dibenzofuran, maltol), and protein (e.g., indoles, pyrroles). The compounds produced from the pyrolytic decomposition of humus acids also include aromatics, polyaromatics, phenols and alkanes (alkenes). In the molecules of humic substances isolated from different coastal environments, Zhang et al. [19], next to the groups of compounds mentioned earlier, identified nittriles, amides and sulphurcontaining compounds.

As reported in literature [6], in soil environments compounds that are phenol-like with different substituent ring groups can be produced as a result of microbiological lignin decomposition, transformations of other phenols derived from higher plants and microorganisms synthesis. An important group is also made up of aromatic hydrocarbons with a single, two or a few condensed rings that can come directly from lignin and products of their partial decomposition. Saiz-Jimenez [23] has noted that a high content of aromatic hydrocarbons in pyrolysis products can be a result of the reactions of decarboxylation and cyclization of fatty acids. Ceccanti et al. [24] and Vancampenhout et al. [21] show that benzene is the key product of pyrolytic degradation of condensed aromatic structures, whereas toluene comes from non-condensed aromatic rings with aliphatic chains. Undoubtedly, the greatest part of the products of pyrolysis of humic acids identified and isolated from soils constitute lignin-derivatives [15-16, 25-26]. Fabbri et al. [16], investigating the products of pyrolysis of humic acids and humins of various origin, showed that toluene plays a dominant role. Its share ranged from 16.4 (HAs of the lagoon) to $38.1 \%$ (HAs of the seas), whereas the HAs of soils accounted for $19 \%$. Gobbels and Puttmann [27], on the other hand, point to a high share of benzene in the products of pyrolysis of humic and fulvic acids.

In the experiment reported by Fabbri et al. [16], 2-methoxyphenol (guaicol) and 2,6-dimethoxyphenol (syringol) were considered the key components of pyrolytic lignin decomposition. The content of the first one ranged from $0.42 \%$ for lagoon HAs to $4.24 \%$ for soil HAs, while the content of syringol ranged from $0.30 \%$ (HAs for the seas) to $3.74 \%$ (soil HAs).

As one can see from the literature review presented, applying the pyrolysis method in association with gas chromatography and mass spectrometry (Py-GC/MS) allows for a detailed determination of the humic substances structure, mainly in the elucidation of the origin of structural components. The aim of the present paper has been to define the importance of the Py-GC/MS method in the study of structural composition of HAs of forest soils depending on the properties of plant litter (oak, spruce, thuja).

\section{Materials and Methods}

The research involved the forest soil sampled from the area of the Rogow Forest Experiment Department (FED), Warsaw Agricultural University (WAU), FED WAU is located in the northeastern part of the Lodz Uplands, between $51^{\circ} 45^{\prime}$ and $51^{\circ} 55^{\prime}$ 'northern altitude and between $19^{\circ} 50^{\prime}$ and $20^{\circ} 10^{\prime}$ eastern longitude.

Forest soil (Haplic Luvisols) was sampled in 5 replications under the following tree stands (about 90 years old):

\begin{tabular}{|c|c|c|c|}
\hline & $\begin{array}{c}\text { Oak stand } \\
\text { (Quercus } \\
\text { robur L.) }\end{array}$ & $\begin{array}{c}\text { Spruce stand } \\
\text { (Picea abies } \\
\text { L. Karsten) }\end{array}$ & $\begin{array}{c}\text { Thuja stand } \\
\text { (Thuja plicata } \\
\text { D.Don.ex. Lamb.) }\end{array}$ \\
\hline $\begin{array}{c}\text { Tree layer } \\
\text { cover [\%] }\end{array}$ & 75 & 75 & 85 \\
\hline $\begin{array}{c}\text { Shrubbery } \\
\text { layer cover } \\
{[\%]}\end{array}$ & 15 & 30 & - \\
\hline $\begin{array}{c}\text { Green plants } \\
\text { layer cover } \\
{[\%]}\end{array}$ & 30 & 25 & 10 \\
\hline $\begin{array}{c}\text { Mossy layer } \\
\text { cover [\%] }\end{array}$ & 5 & 50 & 5 \\
\hline
\end{tabular}

\section{Methods}

Humic acids (HAs) were extracted and purified according to standard methods using the following procedure: 
Table 1. Elemental composition and spectrometric parameters of humic acids.

\begin{tabular}{|c|c|c|c|c|c|c|c|c|c|}
\hline \multirow{2}{*}{$\begin{array}{l}\text { Sample } \\
\text { symbol }\end{array}$} & \multirow{2}{*}{$\begin{array}{l}\text { Horizon (Depth) } \\
\text { (cm) }\end{array}$} & $\mathrm{C}$ & $\mathrm{H}$ & $\mathrm{N}$ & $\mathrm{O}$ & \multirow[t]{2}{*}{$\mathrm{H} / \mathrm{C}$} & \multirow[t]{2}{*}{$\mathrm{O} / \mathrm{H}$} & \multirow[t]{2}{*}{$\mathrm{A}_{2 / 4}$} & \multirow[t]{2}{*}{$\mathrm{A}_{4 / 6}$} \\
\hline & & \multicolumn{4}{|c|}{ Atomic \% } & & & & \\
\hline \multicolumn{10}{|c|}{ Oak stand } \\
\hline RD01 & $\mathrm{Ol}(5-4)$ & $32.7 \pm 0.42 a$ & $47.6 \pm 0.75 b$ & $1.6 \pm 0.04 a$ & $18.1 \pm 0.51 a$ & $1.46 b$ & $0.38 a$ & $8.8 b$ & $8.0 b$ \\
\hline RD1 & $\mathrm{A}(0-8)$ & $32.1 \pm 0.75 a$ & $46.4 \pm 0.42 a$ & $2.3 \pm 0.15 b$ & $19.2 \pm 0.62 b$ & $1.45 b$ & $0.41 b$ & $5.9 a$ & $5.6 a$ \\
\hline RD2 & $\mathrm{E}(20-30)$ & $33.7 \pm 0.44 b$ & $45.7 \pm 0.71 a$ & $2.4 \pm 0.15 b$ & $18.2 \pm 0.50 a$ & $1.36 a$ & $0.40 a b$ & $5.5 a$ & $5.3 a$ \\
\hline \multicolumn{10}{|c|}{ Spruce stand } \\
\hline RS01 & $\mathrm{Ol}(7-5)$ & $33.2 \pm 0.40 a$ & $47.4 \pm 0.79 c$ & $1.7 \pm 0.10 a$ & $17.7 \pm 0.62 a$ & $1.43 c$ & $0.37 a$ & $7.6 c$ & $7.7 c$ \\
\hline $\mathrm{RS} 1$ & $A(0-3)$ & $33.4 \pm 0.55 a$ & $43.4 \pm 0.60 a$ & $1.7 \pm 0.18 a$ & $21.5 \pm 0.80 c$ & $1.30 a$ & $0.50 c$ & $6.1 b$ & $7.1 b$ \\
\hline $\mathrm{RS} 2$ & $\mathrm{AE}(3-20)$ & $33.4 \pm 0.42 a$ & $44.6 \pm 0.72 b$ & $2.1 \pm 0.22 b$ & $19.9 \pm 0.70 b$ & $1.34 b$ & $0.45 b$ & $4.8 a$ & $5.3 a$ \\
\hline \multicolumn{10}{|c|}{ Thuja stand } \\
\hline RT01 & $\mathrm{Ol}(3-2)$ & $34.9 \pm 0.64 b$ & $45.2 \pm 0.59 c$ & $1.2 \pm 0.04 a$ & $18.7 \pm 0.65 a$ & $1.30 b$ & $0.41 a$ & $5.4 b$ & $8.8 c$ \\
\hline RT1 & $A(0-5)$ & $33.0 \pm 0.56 a$ & $44.6 \pm 0.55 b$ & $1.9 \pm 0.16 b$ & $20.5 \pm 0.70 b$ & $1.35 c$ & $0.46 b$ & $5.9 b$ & $6.3 b$ \\
\hline RT2 & E $(18-40)$ & $35.6 \pm 0.69 c$ & $42.9 \pm 0.70 a$ & $2.3 \pm 0.20 c$ & $19.2 \pm 0.72 a$ & $1.20 a$ & $0.45 a b$ & $4.6 a$ & $5.1 a$ \\
\hline
\end{tabular}

* values followed by the same letter are not significantly different at $5 \%$ level

\pm indicates the standard deviation value

- Decalcification $(24 \mathrm{~h})$ with $0.05 \mathrm{M} \mathrm{HCl}(1: 10 \mathrm{w} / \mathrm{v})$. After centrifugation the residue was washed with distilled water until neutral.

- Extraction $(24 \mathrm{~h})$ of the remaining solid with $0.5 \mathrm{M}$ $\mathrm{NaOH}(1: 10 \mathrm{w} / \mathrm{v})$, with occasional mixing, followed by centrifugation.

- Precipitation (24 h) of humic acids from the resulting alkaline extract with $2 \mathrm{M} \mathrm{HCl}$ to $\mathrm{pH}=2$ and centrifugation.

- Purification of the resulting humic acids: the humic acid residue was treated with a mixture of $\mathrm{HCl} / \mathrm{HF}$ (950 mL $\left.\mathrm{H}_{2} \mathrm{O}, 5 \mathrm{~mL} \mathrm{HCl}, 5 \mathrm{~mL} \mathrm{HF}\right)$ over a $24 \mathrm{~h}$ period, followed by centrifugation. This procedure was repeated three times. The humic acids residue was treated with distilled water until a zero reaction to chloride was achieved.

The preparations were lyophilized and powdered in agate mortar. Ash content in the humic acids preparations was lower than $2 \%$.

The separated humic acids were analyzed for:

- Elemental composition (Perkin Elmer $2400 \mathrm{CHN}$ analyser). The $\mathrm{H} / \mathrm{C}$ and $\mathrm{O} / \mathrm{C}$ atomic ratios were calculated.

- UV-VIS absorption spectra (Perkin Elmer UV-VIS Spectrometer, Lambda 20). VIS spectra were obtained from $0.02 \%$ humic acid solutions in $0.1 \mathrm{M} \mathrm{NaOH}$ and UV-spectra after five-fold dilution. Absorbance was measured at $280 \mathrm{~nm}\left(\mathrm{~A}_{280}\right)$, $465 \mathrm{~nm}\left(\mathrm{~A}_{465}\right)$, and $665 \mathrm{~nm}\left(\mathrm{~A}_{665}\right)$ was used to calculate the coefficient values:

$\mathrm{A}_{2 / 4}-280 \mathrm{~nm}$ and $465 \mathrm{~nm}$ absorbance ratio

$\mathrm{A}_{4 / 6}-465 \mathrm{~nm}$ and $665 \mathrm{~nm}$ absorbance ratio

The Py-GC/MS analysis covered humic acids isolated from horizons $\mathrm{Ol}, \mathrm{A}$, and $\mathrm{E}(\mathrm{AE})$, and thus only such data of HAs on those horizons is provided in Table 1.

The analysis of mass spectra of the humic acids was performed by applying a gas chromatograph Turbo Mass Gold Instrument by Perkin Elmer and pyrolyser Pyrojector II provided by SGE. HAs pyrolysis was made at $770^{\circ} \mathrm{C}$. The products of pyrolysis were directly transferred to a silicon chromatographic column Elite - 5MS provided by Perkin Elmer, $30 \mathrm{~m}$ long, $0.25 \mathrm{~mm}$ in internal diameter and $0.25 \mu \mathrm{m}$ film thickness. Helium was used as carrier gas at flow of $1.5 \mathrm{~mL} / \mathrm{min}$. For the MS analysis, the following temperature program was applied:

- Initial furnace temperature of $40^{\circ} \mathrm{C}$ kept for $5 \mathrm{~min}$.

- Increase in temperature of $10^{\circ} \mathrm{C} / \mathrm{min}$ to $300^{\circ} \mathrm{C}$.

- End temperature kept for $15 \mathrm{~min}$.

The conditions for mass spectrometer were as follows: ions source temperature $150^{\circ} \mathrm{C}$, electron energy $70 \mathrm{eV}$.

The products of pyrolysis have been identified by applying the NIST mass spectra libraries and the comparison with literature data [18, 20-21, 25, 27-28]. The relative intensity (Cij) of each compound in every sample was calculated [20]:

$$
\mathrm{Cij}=(\mathrm{Xij} / \Sigma \mathrm{Xi}) 100
$$

...where $\mathrm{Xij}$ is the integrated pyrogram surface for compound " $\mathrm{j}$ " in sample " $\mathrm{i}$ " and $\Sigma \mathrm{Xi}$ is the sum of all the integrated compounds.

The results were exposed to statistical analysis by calculating the standard deviation $( \pm \mathrm{SD})$ of the elemental composition as well as the significance of differences of the basic humic acids parameters, depending on the 
a)

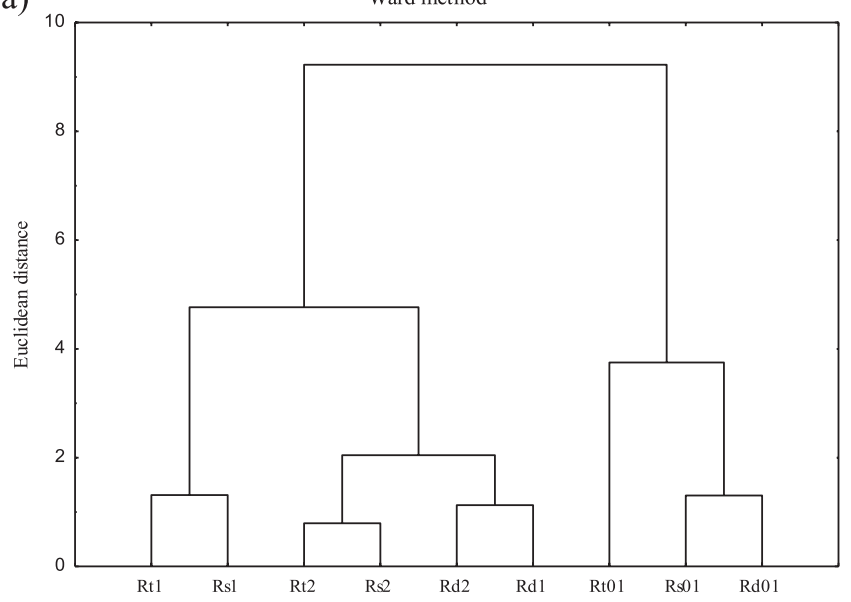

b)

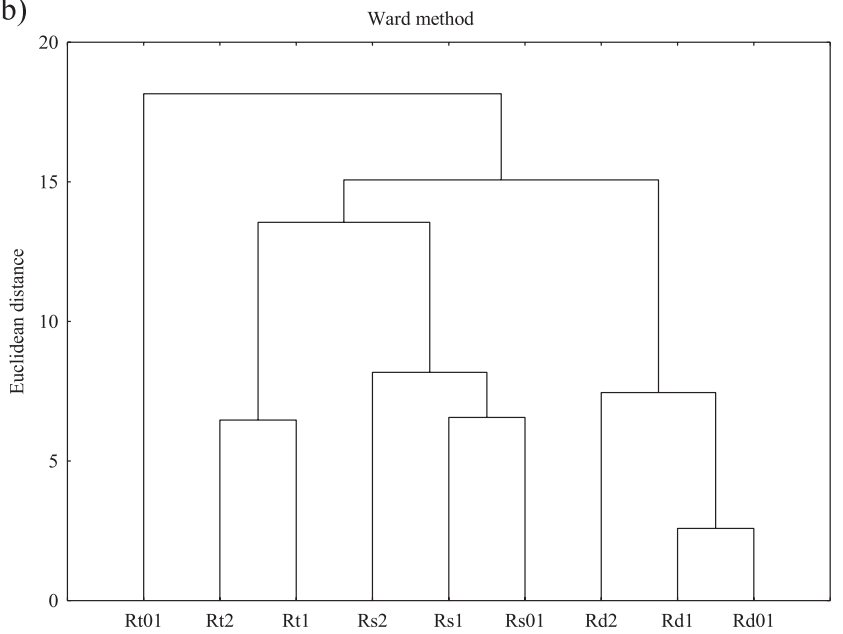

Fig. 1. Cluster analysis of humic acids: a) Determined based on the following parameters: N, O, H/C, O/H, $A_{2 / 4}, A_{4 / 6}$, b) Determined based on the chemical composition of pyrolysis products.

depth (horizon) with Duncan's method. The dependence between the chemical composition of humic acids and the tree stand species was defined with cluster analysis (Fig. 1). The above relationships were determined using statistics software STATISTICA MS.

\section{Results and Discussion}

The plant residue reaching soil at the same time undergoes mineralization and humification. The pattern of organic material mineralization depends on chemical composition and morphology, as well as habitat-and-climate conditions. However, the parameter most frequently applied to evaluate the susceptibility of the plant material to decomposition is the carbonto-nitrogen ratio $(\mathrm{C} / \mathrm{N})[4,6-7,10]$. It is assumed that the higher the initial nitrogen content and the narrower the $\mathrm{C} / \mathrm{N}$ ratio, the more intensive the pattern of mineralization. According to the research presented by Banach-Szott et al. [29], the plant material in the thuja stand is characterized by much higher $\mathrm{C} / \mathrm{N}$ values than the plant material in the oak and spruce stands.

\section{Basic Parameters of Humic Acids}

The process of plant material humification is closely related to an increase in the content of carbon and oxygen as well as a decrease in the content of hydrogen in humic acid molecules [1]. As reported in Table 1, the lowest oxygen (except for the oak stand) and nitrogen as well as the highest content of hydrogen were recorded for HAs isolated from horizon $\mathrm{Ol}$. The results definitely show that the higher the level of humification in the molecules of humic acids, the lower the content of hydrogen and the higher the content of nitrogen. Besides humic acids of the soil mineral horizons, except for HAs in oak stand, showed a higher content of oxygen, as compared with the ectohumus HAs. The content of carbon in humic acids in the spruce stand was unchanging, which differs from the common concept that the greater the progress of humification, the higher the carbon content in HAs molecules. Interestingly, however, the degree of changes in the elemental composition and their direction is not definite, which, e.g., Debska et al. [3] consider to depend on the chemical composition of plant materials undergoing the process of humification. Humic acids isolated from soil sampled from oak and thuja stands demonstrated a higher carbon content in horizons E, as compared with HAs of horizon Ol. As mentioned earlier, mineral horizons HAs showed a higher nitrogen content as compared with humic acids of ectohumus. Although it is rarely the case that humification is connected with an increase in nitrogen content in HAs molecules, the present results confirm the dependence recorded by Debska et. al. [3], showing that higher-maturity HAs show a higher content of nitrogen as compared with "young" newly produced humic acids.

Changes in the elemental composition are accompanied by changes in atomic ratios (Table 1). The H/C ratio values ranged from 1.20 to 1.46 . As reported by Tinoco et al. [14], Ferreira et al. [6], with low values of ratio $\mathrm{H} / \mathrm{C}$, HAs molecules are dominated by aromatic/unsaturated carbon, with high values of $\mathrm{H} / \mathrm{C}$ - aliphatic carbon. The humic acids of horizon $\mathrm{Ol}$ demonstrated, in general, higher values of ratio $\mathrm{H} / \mathrm{C}$, as compared with the humic acids of the other horizons (Table 1). A decrease in the value of ratio $\mathrm{H} / \mathrm{C}$ points to an increase in the level of aromaticity of the humic acids isolated from mineral soil horizons.

Drawing on the values of the atomic ratios of the elements, with some approximation one can assume that values $\mathrm{H} / \mathrm{C}$ and $\mathrm{O} / \mathrm{H}$ did not depend on the tree stand species. Only the humic acids in the thuja stand showed a lower value of ratio $\mathrm{H} / \mathrm{C}$ in horizons $\mathrm{Ol}$ and 
Table 2. Pyrolisis-GC/MS-compounds found in the studied humic acid samples and compound code.

\begin{tabular}{|c|c|c|c|}
\hline Code & Name & Code & Name \\
\hline $\mathrm{Al}$ & Aliphaty & \multicolumn{2}{|c|}{ Lignins compounds (Lg) } \\
\hline \multicolumn{2}{|c|}{ Aromatics (Ar) } & Gul & Guaicol \\
\hline Ar1 & Benzene & $\mathrm{Gu} 2$ & 4-methylguaicol \\
\hline Ar2 & Toluene & Gu3 & 4-vinylguaicol \\
\hline Ar3 & Xylene & $\mathrm{Gu} 4$ & 4-formylguaicol vanillin \\
\hline Ar4 & Propylobenzene & Gu5 & Vannilic acids \\
\hline Ar5 & Indene & Sy1 & Syringol \\
\hline Ar6 & 1-methyl-1H-indene & Sy2 & 4-methylsyringol \\
\hline Ar7 & 1H-indene-dimethyl & Sy3 & 4-(prop-1-enyl)syringol \\
\hline \multicolumn{2}{|c|}{ Polyaromatics $(\mathrm{Pa})$} & Sy4 & vinylsyringol \\
\hline Pa1 & Naphtalene & \multicolumn{2}{|c|}{ Polysaccharide compounds (Ps) } \\
\hline $\mathrm{Pa} 2$ & Phenanthrene-3-methyl & Ps1 & Maltol \\
\hline $\mathrm{Pa} 3$ & $\mathrm{x}$-methyl naphtalene & Ps2 & Ethylbenzofuran \\
\hline \multicolumn{2}{|c|}{ Phenols (Ph) } & Ps3 & Furan-3phenyl \\
\hline Ph1 & Phenol & \multicolumn{2}{|c|}{ N-Compounds (N) } \\
\hline $\mathrm{Ph} 2$ & Dimethylphenol & N1 & Benzenonitrile \\
\hline $\mathrm{Ph} 3$ & 3/4ethylphenol & & \\
\hline $\mathrm{Ph} 4$ & 4-vinylphenol & & \\
\hline
\end{tabular}

E, as compared with the HAs isolated from oak and spruce stands. Parameter $\mathrm{O} / \mathrm{H}$ is one of the indicators of humic acid molecule oxidation. The higher the value of ratio $\mathrm{O} / \mathrm{H}$ (similarly as $\mathrm{H} / \mathrm{C}$ ), the higher the level of humic acid maturity [3, 6]. The values of ratio $\mathrm{O} / \mathrm{H}$, irrespective of the tree stand species, were higher for HAs of mineral horizons as compared with HAs of horizon Ol (Table 1).

Much valuable information on the advancement of the humification process is provided by the values of ratio of absorbance $\mathrm{A}_{2 / 4}, \mathrm{~A}_{2 / 6}$ and $\mathrm{A}_{4 / 6}$, as well as parameter $\Delta \log \mathrm{K}$. It is assumed that humic acids with a low maturity level, isolated from materials with a low humification level, show higher values of coefficients $\mathrm{A}_{2 / 4}, \mathrm{~A}_{2 / 6}, \mathrm{~A}_{4 / 6}$ and $\Delta \operatorname{logK}$ as compared with HAs molecules with a higher humification level and a higher content of aromatic compounds [12-14].

With the values of coefficients $\mathrm{A}_{2 / 4}$ and $\mathrm{A}_{4 / 6}$ (Table 1) we found that humic acids of horizon $\mathrm{Ol}$ demonstrated a lower maturity level as compared with humic acids of mineral horizons. The highest maturity level was recorded for the HAs isolated from horizon E (AE). Values of those coefficients were also determined by the stand tree species, with the lowest values of ratio $\mathrm{A}_{2 / 4}$ recorded for HAs in the thuja stand. The values of ratio $A_{4 / 6}$ were highest for HAs of horizon $\mathrm{Ol}$ in the thuja stand, and for that stand we recorded the highest changes in the values of that coefficient.

\section{Py-GC/MS Analysis of Humic Acids}

It is known that humic acids isolated from soils are macro-molecules formed as a result of the decomposition of plant residue, forest litter or natural fertilizers (FYM, slurry) [5, 15, 20-21]. Therefore the precursors of humus substances can include various groups of organic compounds; lignins, cellulose, hemicelulloses and monosaccharides, waxes, resins, and chitin, as well as microorganism metabolism products. Determining the origin of compounds being part of the molecules of humus substances is possible by identifying the compounds formed as a result of pyrolysis of humus substances [20-22]. As seen from the data reported in Table 2, the products of pyrolysis of humic acids were identified as single-ring and polycyclic aromatic compounds, lignin-derived compounds, phenolic compounds, polysaccharides, and nitrogen-containing compounds, as well as aliphatic compounds.

The dominant compounds included in the products of decomposition of humic acids were single-ring aromatic hydrocarbons, which accounted for 58.81 to $76.20 \%$ of all the compounds identified (Table 3). Aliphatic compounds ranged from 4.02 to $21.03 \%$. The share of phenols ranged from 1.59 to $8.88 \%$. The content of benzenonitrile compound, which was the only one classified as $\mathrm{N}$-compounds, ranged from 4.62 to $7.91 \%$. Lignin compounds accounted for 2.64 to $5.98 \%$. The lowest share was recorded for the 
compounds of polysaccharides origin: from 0.60 to $3.22 \%$. A considerable share of aromatic compounds in the products of pyrolysis of humus acids was recorded by, e.g., Fabbri et al. [16], Zhang et al. [19], and Gobbels and Puttmann [27].
Of all the single-ring aromatic hydrocarbons, the highest share was found for benzene and toluene, and among polyaromatics among x-methyl naphtalene. In the group of phenols, it was dimethylphenol that dominated. Among the compounds considered to be lignin

Table 3. Share (\%) of pyrolysis-GC/MS-compounds found in the humic acid samples.

\begin{tabular}{|c|c|c|c|c|c|c|c|c|c|}
\hline Code & $\mathrm{Rd} 01$ & Rd1 & $\mathrm{Rd} 3$ & RS01 & RS1 & $\mathrm{RS} 2$ & RT01 & RT1 & RT3 \\
\hline $\mathrm{Al}$ & 11.08 & 16.12 & 21.03 & 11.8 & 8.58 & 15.05 & 4.02 & 9.55 & 13.72 \\
\hline Ar1 & 26.08 & 25.04 & 24.11 & 21.80 & 23.02 & 22.60 & 27.80 & 27.31 & 24.44 \\
\hline Ar2 & 20.99 & 19.51 & 22.54 & 21.99 & 24.50 & 25.96 & 26.15 & 17.18 & 18.08 \\
\hline Ar3 & 3.40 & 3.06 & 2.39 & 3.90 & 3.28 & 4.02 & 7.99 & 3.61 & 3.91 \\
\hline Ar4 & 2.70 & 2.77 & 2.68 & 2.42 & 2.26 & 2.52 & 0.24 & 1.69 & 1.59 \\
\hline Ar5 & 7.80 & 7.79 & 6.74 & 9.46 & 7.47 & 5.01 & 8.48 & 6.94 & 5.88 \\
\hline Ar6 & 5.85 & 5.35 & 3.81 & 4.00 & 5.52 & 4.14 & 5.54 & 4.89 & 4.66 \\
\hline Ar7 & 0.17 & 0.18 & 0.06 & 0.22 & 0.18 & 0.06 & 0 & 0.10 & 0.25 \\
\hline Sum & 66.99 & 63.7 & 62.33 & 63.79 & 66.23 & 64.31 & 76.2 & 61.72 & 58.81 \\
\hline Pal & 0.92 & 0.64 & 0.56 & 0.71 & 0.61 & 0.69 & 0.13 & 0.49 & 0.63 \\
\hline $\mathrm{Pa} 2$ & 0.24 & 0.48 & 0.31 & 0.17 & 0.16 & 0.19 & 0.03 & 0.35 & 0 \\
\hline $\mathrm{Pa} 3$ & 4.44 & 3.78 & 2.78 & 3.23 & 3.43 & 2.97 & 2.10 & 3.17 & 6.85 \\
\hline Sum & 5.6 & 4.9 & 3.65 & 4.11 & 4.2 & 3.85 & 2.26 & 4.01 & 7.48 \\
\hline $\mathrm{Ph} 1$ & 0.43 & 0.18 & 0.34 & 0.87 & 4.15 & 0.58 & 1.13 & 4.50 & 3.43 \\
\hline $\mathrm{Ph} 2$ & 1.38 & 2.53 & 0.64 & 4.64 & 3.02 & 1.50 & 1.35 & 4.38 & 3.01 \\
\hline $\mathrm{Ph} 3$ & 0.13 & 0.22 & 0.56 & 0.64 & 0.48 & 0.51 & 0.15 & 0 & 0 \\
\hline $\mathrm{Ph} 4$ & 0.09 & 0.08 & 0.05 & 0.24 & 0.16 & 0.27 & 0.16 & 0 & 0 \\
\hline Sum & 2.03 & 3.01 & 1.59 & 6.39 & 7.81 & 2.86 & 2.79 & 8.88 & 6.44 \\
\hline Gu1 & 0.23 & 0.18 & 0.31 & 0.44 & 0.28 & 0.31 & 0.55 & 1.25 & 0.04 \\
\hline $\mathrm{Gu} 2$ & 0.56 & 0.28 & 0.39 & 0.27 & 0.22 & 0.22 & 0.50 & 0.45 & 0.29 \\
\hline Gu3 & 1.11 & 0.81 & 0.69 & 0.75 & 0.60 & 0.67 & 0.91 & 0.90 & 0.99 \\
\hline $\mathrm{Gu} 4$ & 0.89 & 0.66 & 0.56 & 0.95 & 0.75 & 0.66 & 0.60 & 0.61 & 0.66 \\
\hline Gu5 & 0.09 & 0.10 & 0.08 & 0.15 & 0.10 & 0.05 & 0.04 & 0.10 & 0.07 \\
\hline Sum & 2.88 & 2.03 & 2.03 & 2.56 & 1.95 & 1.91 & 2.6 & 3.31 & 2.05 \\
\hline Sy1 & 0.52 & 0.30 & 0.24 & 0.36 & 0.32 & 0.27 & 0.08 & 0.24 & 0.21 \\
\hline Sy2 & 0.26 & 0.03 & 0.29 & 0.39 & 0.03 & 0.08 & 0.10 & 0.42 & 0.97 \\
\hline Sy3 & 0.10 & 0.18 & 0.12 & 0.07 & 0.06 & 0.11 & 0 & 0.04 & 0 \\
\hline Sy4 & 0.55 & 0.80 & 0.41 & 0.24 & 0.28 & 1.09 & 0.07 & 1.97 & 0.15 \\
\hline Sum & 1.43 & 1.31 & 1.06 & 1.06 & 0.69 & 1.55 & 0.25 & 2.67 & 1.33 \\
\hline $\mathbf{G u}+\mathbf{S y}$ & 4.31 & 3.34 & 3.09 & 3.62 & 2.64 & 3.46 & 2.85 & 5.98 & 3.38 \\
\hline Ps 1 & 0.63 & 0.56 & 0.48 & 1.03 & 1.19 & 1.30 & 0.26 & 0.78 & 0.84 \\
\hline Ps2 & 0.10 & 0 & 0.08 & 0.22 & 0.24 & 0.15 & 0.31 & 0.16 & 0.32 \\
\hline Ps3 & 0.42 & 0.48 & 0.04 & 0.76 & 1.11 & 0.58 & 0.80 & 0.99 & 2.06 \\
\hline Sum & 1.15 & 1.04 & 0.6 & 2.01 & 2.54 & 2.03 & 1.37 & 1.93 & 3.22 \\
\hline N1 & 5.96 & 5.86 & 5.68 & 5.72 & 6.05 & 6.53 & 7.91 & 4.62 & 4.90 \\
\hline
\end{tabular}


compounds, the share of guaicol and its derivatives was higher than syringol and its derivatives. In general, irrespective of the sample origin, the highest share in that group of compounds was found for vinylguaicol. At the same time, interestingly, the greater the depth, the lower the share of guaicol in the molecules of humic acids, for instance, which is connected with a decrease in the share of undecomposed lignin structures [18, 20-21]. That transformation confirms a considerable role of lignins in the process of humic acid formation $[5-6,9,15,25,27]$. One shall also highlight that an important group of compounds of lignin origin is made up of phenols; however - as recorded by Vancampenhout et al. [20-21] - phenols can also be of microbial origin. Martinez-Balmori et al. [5] and DiDonato et al. [9] stress that the process of lignin transformation in the process of humification can lead to the formation of aliphatic compounds. Irrespective of the tree stand species, the higher the maturity level (with depth) of the molecules of humic acids, the higher the share of aliphatic compounds. The changes in the other groups of compounds were connected with the soil sampling site, namely with plant material properties. An essential role of the properties of plant material in developing HAs properties of mineral horizons is reported by Duarte et al. [11], based on the study of the structure of humic acids of horizon $\mathrm{Ol}$ and mineral horizons of soils in oak and spruce stands. This paper reports on the oak stand where the HAs molecules isolated from the soil sampled from horizon $\mathrm{Ol}$, as compared with HAs of horizon E, demonstrated:

- A higher share of aromatic compounds due to a decreased, with depth, share of benzene, xylene, and indene derivatives (Ar5 and Ar6).

- A lower share of polyaromatics due to a decrease, with depth, of naphtalene and x-methyl naphtalene.

- A higher share of syringol and its derivatives.

- A higher share of polysaccharide compounds.

- A higher share of the sum of phenols, mostly related to a considerable decrease in dimethylphenol.

In the molecules of humic acids in the spruce stand, unlike HAs in the oak stand, there was found no considerable difference in the content of the sum of aromatics between samples RS01 and RS2. The highest content of the sum of aromatics was found for the humic acids isolated from the soil sampled from horizon A. HAs of horizon AE showed a higher share of syringol derivatives as compared with HAs of horizon Ol. Besides, in the HA molecules in spruce stand, with increasing soil sampling depth, there was noted an increase in the share of $\mathrm{N}$-compounds. In the thuja stand, unlike HAs in oak and the spruce stand, we recorded an increase in the share of polyaromatics due to an increase in mostly $\mathrm{x}$-methyl naphtalene as well as an increase in phenol and dimethylphenol. Additionally, there was recorded a decrease in benzenonitrile by 3.01 percentage points. One shall note a much higher content of phenols in conifers stands as compared with HAs in oak stand (Table 3).
To acquire complete information on differences (similarities) in the chemical composition of humic acids, depending on the soil sampling site, (the tree stand species), cluster analysis was applied. Cluster analysis was performed based on basic parameters of humic acids; elemental composition $(\mathrm{H} / \mathrm{C}, \mathrm{O} / \mathrm{H}, \mathrm{N})$ as well as $\mathrm{A}_{2 / 4}$ and $\mathrm{A}_{4 / 6}$ divided humic acids into two major groups; one with humic acids of horizon $\mathrm{Ol}$ and the other with HAs of horizons A and E (AE) (Fig. 1a). Among the HAs of horizon Ol, the molecules of humic acids in oak and spruce stands showed the highest similarity to each other than to the HAs of horizon $\mathrm{Ol}$ in the thuja stand. The division of HAs made in the latter group points to significant differences between HAs properties of horizons $\mathrm{A}$ and $\mathrm{AE}$ in oak stand and the HAs isolated from the soil sampled from conifer stands.

Performing cluster analysis, drawing on the share of pyrolysis products, divides the humic acids into three subgroups (Fig. 1b); one is made up of the HAs isolated from soil sampled from the oak stand, the other one is HAs sampled from the spruce stand and the third is the HAs from the thuja stand. In addition, the dendrograms point to significant differences in the chemical composition between oak HAs (deciduous trees) and spruce and thuja HAs (the conifers). In oak and spruce stands the chemical composition of HAs in horizon A showed a greater similarity to the composition of HAs in horizon $\mathrm{Ol}$ than $\mathrm{E}$ (AE), unlike humic acids in the thuja stand, where the highest similarity of the chemical composition was noted between the HAs of horizons $A$ and E. One shall also stress that the chemical composition of humic acids isolated from the samples of horizon $\mathrm{Ol}$ in the thuja stand differed most from the other HAs.

\section{Conclusions}

This research definitely points to the dominant role of the properties of plant litter in developing the properties of soil organic matter (SOM). Determining the properties and structure of the molecules of humic acids facilitates determining their stability and, as a result, forecasting the reserves of soil organic carbon [30]. The highest share of aliphatic compounds was recorded for humic acids of both mineral horizons and horizon $\mathrm{Ol}$ in oak stand and the lowest in the thuja stand. The share of aliphatic compounds in the molecules of HAs in horizon $\mathrm{E}$ in the thuja stand was similar to the share of that group of compounds in HAs of horizon AE in the spruce stand. In the thuja stand the humic acids of mineral horizons show a lower share of single-ring aromatic compounds as compared with HAs in oak and spruce stands. However, a higher (horizon E) X-methyl naphtalene a compound has two condensed rings. One can thus state that the process of plant material humification in thuja leads to the formation of humic acids with a higher stability than oak and spruce. The comparison of the share of respective groups of 
compounds in the molecules of humic acids of mineral horizons in oak and spruce stands points to a higher stability of humic acids in spruce (a higher share of aromatic compounds and a lower share of aliphatic compounds).

\section{Conflict of Interest}

The authors declare no conflict of interest.

\section{References}

1. TAN H.K., Humic matter in soil and the environment, $2^{\text {nd }}$ edn. CRC Press, Boca Raton, 463, 2012.

2. SJOBERG G., NILSSON S.I., PERSSON T., KARLSSON P. Degradation of hemicellulose, cellulose and lignin in decomposing spruce needle litter in relation to N. Soil Biol. Biochem. 36, 1761, 2004. doi:10.1016/j. soilbio.2004.03.010

3. DEBSKA B., DRAG M., TOBIASOVA E. Effect of postharvest residue of maize, rapeseed, and sunflower on humic acids properties in various soils. Pol. J. Environ. Stud. 21 (3), 603, 2012.

4. KASAHARA M., FUJII S., TANIKAWA T., MORI A.S. Ungulates decelerate litter decomposition by altering quality above and below ground. Eur. J. Forest Res. 135, 849, 2016. doi:10.1007/s10342-016-0978-3

5. MARTINEZ-BALMORI D., SPACCINI R., AGUIAR N.O., NOVOTNY E.H., OLIVARES F.O., CANELLAS L.P. Molecular characteristics of humic acids isolated from vermicomposts and their relationship to bioactivity. J. Agric. Food Chem. 62, 11412, 2014. dx.doi.org/10.1021/ jf504629c

6. FERREIRA F.P., VIDAL-TORRADO P., OTERO X. L, BUURMAN P., MARTIN-NETO L., BOLUDA R., MACIAS F. Chemical and spectroscopic characteristics of humic acids in marshes from the Iberian Peninsula. J. Soils Sediments 13, 253, 2013. doi:10.1007/s11368-012-0607-9

7. STAHR S., GRAF-ROSENFELLNER M., KLYSUBUN W., MIKUTTA R., PRIETZEL J., LANG F. Phosphorus speciation and C:N:P stoichiometry of functional organic matter fractions in temperate forest soils. Plant Soil 427, 53, 2018. doi:10.1007/s11104-017-3394-7

8. KOGEL I., HEMPFFLING R., ZECH W., HATCHER P.G., SCHULTEN H.R. Chemical composition of the organic matter in forest soils, 1. Forest litter. Soil Sci. 146 (2), 124,1988

9. DIDONATO N., CHEN H., WAGGONER D., HATCHER P.G. Potential origin and formation for molecular components of humic acids in soils. Geochim. Cosmochim. Ac. 178, 210, 2016. doi:org/10.1016/j.gca.2016.01.013

10. BIMULLER C., MUELLER C. W., VON LUTZOW M., KREYLING O., KOLBL A., HAUG S., SCHLOTER M., KOGEL-KNABNER I. Decoupled carbon and nitrogen mineralization in soil particle size fractions of a forest topsoil. Soil Biol. Biochem. 78, 263, 2014. http://dx.doi. org/10.1016/j.soilbio.2014.08.001

11. DUARTE R.M.B.O., FERNANDEZ-GETINO A.P., DUARTE A.C. Humic acids as proxies for assessing different Mediterranean forest soils signatures using solidstate CPMAS 13C NMR spectroscopy. Chemosphere 91, 1556, 2013. doi:org/10.1016/j.chemosphere.2012.12.043
12. ENEV V., POSPISILOVÁ L., KLUCAKOVA M., LIPTAJ T., DOSKOCIL L. Spectral characterization of selected humic substances. Soil Water Res., 9 (1), 9, 2014. https:// doi.org/10.17221/39/2013-SWR

13. FASUROVA N., POSPISILOVA L. Characterization of soil humic substances by ultraviolet-visible and synchronous fluorescence spectroscopy. J. Cen. Europ. Agr. 11 (3), 351, 2010.

14. TINOCO P., ALMENDROS G., FRANCISCO J., GONZALEZ-VILA F.J., SANZ J., GONZALEZ-PEREZ J.A. Revisiting molecular characteristics responsive for the aromaticity of soil humic acids. J. Soils Sediments 15, 781, 2015. doi:10.1007/s11368-014-1033-y

15. CHIAVARI G., TORSI G., FABBRI D., GALLETTI G.C. Comparative study of humic substances in soil using pyrolytic techniques and other conventional chromatographic methods. Analyst 119, 1141, 1994.

16. FABBRI D., MONGARDI M., MONTANARI L., GALlETTI G.C., CHIAVARI G., SCOTTI R. Comparison between CP/MAS13C-NMR and pyrolysis-GC/MS in the structural characterization of humins and humic acids of soil and sediments. Fres. J. Anal. Chem. 362, 299, 1998.

17. PARSI Z., HARTOG N., GORECKI T., POERSCHMANN J. Analytical pyrolysis as a tool for the characterization of natural organic matter: a comparison of different approaches. J. Anal. Appl. Pyrol. 79, 9, 2007. doi:org/10.1016/j.jaap.2006.10.013

18. DE ASSIS C.P., GONZALEZ-PEREZ J.A., DE LA ROSA J.M., JUCKSCH I., DE SA MENDONCA E., GONZALEZ-VILA F.J. Analytical pyrolysis of humic substances from a Latosol (Typic Hapludox) under different land uses in Minas Gerais. Brazil J. Anal. Appl. Pyrol. 93, 120, 2012.

19. ZHANG Y., DU J., DING X., ZHANG F. Comparison study of sedimentary humic substances isolated from contrasting marine environments by chemical and spectroscopic analysis. Environ. Earth Sci. 75, 378, 2016. doi:10.1007/s12665-016-5263-8

20. VANCAMPENHOUT K., WOUTER K., DE VOS B., BUURMAN P. Differences in chemical composition of soil organic matter in natural ecosystems from different climatic regions - A pyrolysis-GC/MS study. Soil Biol. Biochem. 41, 568-579, 2009. doi:10.1016/j. soilbio.2008.12.023

21. VANCAMPENHOUT K., DE VOS B., WOUTERS K., VAN CALSTER H., SWENNEN R., BUURMAN P., DECKER J. Determinants of soil organic matter chemistry in maritime temperate forest ecosystems Soil Biol. Biochem. 42, 220, 2010. doi:10.1016/j. soilbio.2009.10.020

22. YASSIR I., BUURMAN P. Soil organic matter chemistry changes upon secondary succession in Imperata Grasslands, Indonesia: A pyrolysis - GC/ MS study. Geoderma 173-174, 94, 2012. doi:10.1016/j. geoderma.2011.12.024

23. SAIZ-JIMENEZ C. Analytical pyrolysis of humic substances: pitfalls, limitations and possible solutions. Environ. Sci. Technol. 28, 1773, 1994. doi:10.1021/ es00060a005

24. CECCANTI B., ALCANITZ J.M., GISPERT M., GASSIOT M. Characterization of organic matter from two different soils by pyrolysis-gas chromatography and isoelectric focusing. Soil Sci. 142, 83, 1986.

25. ADANI F., SPAGNOL M., NIEROP K.G. Biochemical origin and refractory properties of humic acid extracted from maize plants: the contribution of lignin. 
Biogeochemistry 82，55，2007. doi:10.1007/s10533-0069052-4

26. IWAI H., FUKUSHIMA M., YAMAMOTO M., KOMAI T., KAWABE Y. Characterization of seawater extractable organic matter from bark compost by TMAH-py-GC/ MS. J. Anal. Appl. Pyrol. 99, 9, 2013. doi:10.1026j. jaap.2012.11.012

27. GOBBELS F.J., PUTTMANN W. Structural investigation of isolated aquatic fulvic and humic acids in seepage water of waste deposits by pyrolysis-gas chromatography/mass spectrometry. Wat. Res. 31 (7), 1609, 1997.

28. GREENWOOD P.F., BERWICK L.J., CROUE J.P. Molecular characterization of the dissolved organic matter of wastewater effluents by MSSV pyrolysis GC-MS and search for source markers. Chemosphere 87, 504, 2012. doi:10.1016/j.chemosphere.2011.12.051

29. BANACH-SZOTT M., DEBSKA B. Content of phenolic compounds in fulvic and humic acid fractions of forest soils. Pol. J. Environ. Stud. 17 (4), 463, 2008.

30. D'ORAZIO V., TRAVERSA A., SENESI N. Forest soil organic carbon dynamics as affected by plant species and their corresponding litters: a fluorescence spectroscopy approach. Plant Soil 374, 473, 2014. doi:10.1007/s11104013-1897-4 